\title{
Title IV-E Child Welfare Training and University Partnerships: Transforming State Child Protection Services into a Trauma-Informed System
}

\author{
Robin Hernandez-Mekonnen \\ Dawn Konrady
}

\begin{abstract}
Children who are involved in the child welfare system have experienced trauma, and research indicates that parents of those children also frequently grapple with their own unresolved trauma. In addition, child welfare workers face high rates of secondary traumatic stress. Federal legislation from 2011 requires states to conduct universal trauma screening on children in foster care. The Administration on Children and Families (ACF) urges state Child Protection agencies (CPS) to become trauma-informed, however, many states still struggle to integrate a trauma focused practice model. This article describes the outcomes of a national, empirically driven, Core Concepts in Child Trauma for Child Welfare curriculum utilized in a Title IV-E university partnership program to teach graduate level child welfare agency supervisors. Findings suggest that the graduate trauma course demonstrates statistically significant gains in confidence, and also has a profound impact on the agency's transformation into a trauma-informed system.
\end{abstract}

Keywords: Title IV-E; child welfare; trauma; secondary traumatic stress; social work education

There is a significant body of research indicating the importance of using a Traumainformed approach in working with maltreated children, yet not all states and jurisdictions have fully engaged in the process of identifying or adapting a model or framework by which they will approach trauma-informed practice (Ai, Foster, Pecora, Delaney, \& Rodriguez, 2013; Hanson \& Lang, 2016; Klain \& White, 2013). As states transition to a trauma-informed approach, there is a need for high caliber evidence based curricula. This study investigates the impact of a statewide Title IV-E MSW consortium utilizing an empirically based trauma curriculum in aiding the early transition into a trauma-informed child protection system.

Child maltreatment research has grown exponentially in the number of studies investigating the nature and prevalence of trauma experienced by the children involved in the child welfare system (Kisiel, Fehrenbach, Small, \& Lyons, 2009; Miller, Green, Fettes, \& Aarons, 2011). In addition to learning about the trauma experienced by children, we have gained insight into the unresolved trauma histories of caregivers, and the secondary traumatic stress experienced by the child welfare workforce (Bride, Jones, \& MacMaster, 2007; Nelson-Gardell \& Harris, 2003). In 2011, President Obama enacted the Child and Family Services Improvement and Innovation Act (2011) which amended language to require States to include a description of how they will screen for, and treat, emotional trauma associated with maltreatment and removal, in the health oversight plan. While the requirement specifies children in foster care, the Administration on Children Families

Robin Hernandez-Mekonnen, PhD, MSW is Associate Professor of Social Work, School of Social and Behavioral Sciences, Stockton University, Galloway, NJ 08205. Dawn Konrady, EdD, MBA, MA, is Director of the Child Welfare Education Institute, Stockton University, Galloway, NJ 08205. 
(ACF) issued an Information Memorandum (IM) to States, Tribes, and Territories suggesting that they integrate trauma screening into the regular developmental screening activities (under Early Periodic Diagnosis and Treatment: EPSDT) in order to meet the new requirement (ACF, 2012). As such, child protection agencies are compelled to seek strategies to become trauma-informed, including specific trauma-informed screening and assessment protocols, and creating access to trauma-informed treatment.

Since 1980, Title IV-E of the Social Security Act has supported the development and implementation of formalized child welfare education programs to increase the number of prepared candidates for careers in child welfare (Zlotnik, 2003). There are currently approximately 40 states receiving Title IV-E funding for education, and nearly all of those states are engaged in university partnerships with academic degree programs (Zlotnik, Strand, \& Anderson, 2009). The range of supports students receive in these programs is notable, some receiving book stipends and others receiving full tuition benefits and salary. However, research indicates IV-E programs are effective in improving Child Protective Services (CPS) worker retention (O'Donnell \& Kirkner, 2009; Zlotnik, 2003; Zlotnik \& Pryce, 2013).

Social work programs are charged with educating IV-E students. Both undergraduate (Bachelor of Social Work - BSW) and graduate (Master of Social Work - MSW) programs serving IV-E students vary in their offerings of courses, or electives that are related to child welfare. This paper discusses the implementation and impact of an evidence-based MSW elective in trauma-informed child welfare practice in a Title IV-E university partnership to aid in the transformation of a state based child welfare system to a trauma-informed system.

\section{Child Traumatic Stress}

Scientific advances in the study of the brain have enhanced the ability to detect the neurological and cognitive impact of childhood trauma on the development of children (Perry, 2009; Watts-English, Fortson, Giblet, Hooper, \& DeBellis, 2006). Traumatic experiences have both short-term and long-term effects upon children, often lasting into their transition into adulthood. Research indicates a clear pathway between childhood trauma and both acute and chronic manifestations of cognitive, emotional, psychiatric, relationship, social, and health outcomes (Richardson, Henry, Black-Pond \& Sloane, 2008). The Centers for Disease Control and Prevention has conducted decades of research investigating the public health repercussions of Adverse Childhood Experiences (Feletti \& Anda, 2014). A multitude of studies reveals the effects of trauma upon long term outcomes, including an array of emotional, behavioral, cognitive, and social, cognitive, emotional and behavioral impairments (Ai et al., 2013; Feletti \& Anda, 2014; Felitti et al., 1998).

According to the New Jersey Department of Children and Families (DCF) Commissioner's Monthly Report, in September 2016, approximately 45,823 children were under the Division of Child Protection and Permanency's supervision, 6,698 were in outof-care settings, with approximately 11,500 new cases of child maltreatment substantiated and opened in the past year (Blake, 2016). By the very nature of coming to the attention of the child protection system, particularly after an investigation has concluded that there is merit for involvement, children have experienced some form of trauma (Ko et al.,2008). 
While the manifestations of trauma are varied, depending on age, trauma type, and the supports the child may receive (Ko et al., 2008), CPS agencies have lacked sufficient resources to adequately address the needs of traumatized children, despite the 2011 law. The resources to address the needs of children experiencing trauma include universal and routine screening of children for symptoms of traumatic stress, access to trauma focused and evidence based interventions, and access to trauma-informed systems of care (ACF, 2012). Trauma-informed child welfare practice, along with quality and trauma focused clinical interventions are crucial components addressing traumatic stress (ACF, 2012).

\section{Caregiver Traumatic Stress}

CPS agencies have undergone decades of reform efforts, often lead by litigation, and class action suits resulting in consent decrees (Noonan, Sabel, \& Simon, 2009). Despite the mandate of the 2011 legislation, the movement toward integrating a social work perspective, accompanied by a trauma-informed focus, is only a recent undertaking by a handful of state child welfare systems. As CPS workers and clinicians begin to align their approaches with a trauma-informed lens, it becomes increasingly evident that the caregivers or parents of the children being screened for trauma, are experiencing parenting deficits, at least in part, due to their own unresolved trauma (Walker, 2007). In fact, many systems still do not conduct universal trauma screening for child victims, so performing trauma screening with birth parents or other caregivers is even more unlikely. Yet, there is a growing body of research linking the experience of child maltreatment (as indicated by CPS involvement) in later childhood or adolescence to the increased likelihood of involvement as a parent in CPS (Thornberry \& Henry, 2013). Most recent data from California indicates at least a $44 \%$ increased likelihood that a mother who conceives between the ages of 15-19 will be reported for child maltreatment before her child reaches five years of age (Putnam-Hornstein, Cederbaum, King, Eastman, \& Trickett, 2015).

While the debate of whether "maltreatment begets maltreatment" continues (Thornberry, Knight, \& Lovegrove, 2012, p.135), research is being done to explore the intergenerational effects of maltreatment upon parenting styles and attachment of adults with their children (Berthelot et al., 2015; Kim, Fonagy, Allen, \& Strathearn, 2014; Schwerdtfeger, Larzelere, Werner, Peters, \& Oliver, 2013). The empirical evidence thus far suggests there are indeed correlations, and CPS professionals in the field struggle with addressing prior trauma histories on cases where perhaps there was a missed opportunity by the system when the caregiver was a child. In states like New Jersey, where the child protection system has a history of failings, cases where parents were former clients as children, are relatively common. As workers learn about case level caregiver trauma and continue to trace history of cases, there is a disheartening realization that that the system failed to adequately address their childhood trauma, and as parents, these former clients still struggle to overcome the effects of unresolved trauma (Kim et al., 2014; National Child Traumatic Stress Network [NCTSN], 2011; Walker, 2007). CPS supervisors find themselves frustrated that the CPS system had an opportunity to intervene, and had a trauma focus been part of the service delivery a decade ago, these children may have had better chances to become healthy adults and parents. Additionally, the level of trust these parents, former clients, have for the CPS system is limited (NCTSN, 2011; Walker, 2007). 
A lack of trust due to failure of the system on their own behalf creates a difficult dynamic for effective engagement by CPS workers.

\section{Secondary Traumatic Stress in CPS workers}

The child welfare workforce is another important consideration in becoming a traumainformed organization. There is a significant body of literature that captures the prevalence and impact of secondary traumatic stress in the human service professions. There are fewer studies that parse out the effects of secondary traumatic stress upon the CPS workforce. Figley (1995) pioneered the term secondary traumatic stress (STS), which he defined as "the natural consequent behaviors and emotions resulting from knowing about a traumatizing event experienced by a significant other" (1995, as cited in Pryce, Shackelford, \& Pryce, 2007, p. 13). He contends that while the causes of STS are different from post-traumatic stress disorder (PTSD), the reactions are equivalent. Figley also identified four criteria that increase one's vulnerability for STS: the actual child's trauma, unresolved personal trauma, any personal trauma history, and one's level of empathy (Pryce et al., 2007). CPS workers experiencing STS are more likely to leave their positions, creating significant cost to the organization and to clients (O'Donnell \& Kirkner, 2009). Recruiting, training and retaining child welfare workers is a significant fiscal burden, and is also costly to their clients in terms of stability and trust (Strolin-Goltzman, Kollar, \& Trinkle, 2010). CPS organizations and clients benefit from taking stock of their current staff and cultivating resources to monitor and support workers who are at an elevated risk for STS (Pryce et al., 2007).

\section{Title IV-E - Master of Social Work and the Masters Child Welfare Education Program (MCWEP) University Partnership}

The New Jersey IV-E partnership is an innovative model to CPS workforce training. After a sordid history of failure in child protection, combined with high profile media exposure and a class action law suit, the New Jersey Department of Children and Families entered a consent decree, a modified settlement agreement, and is currently developing an exit strategy. Under the consent decree, aggressive measures were initiated to recruit hundreds of CPS workers (Lipka \& Graham, 2004). Funds were harnessed for this recruitment effort, as well as training and retention. A state of the art training academy, in collaboration with the MCWEP program, is a key component in the agency's strides in professionalization and retention (Guzkowski, 2015).

MCWEP is a statewide university partnership consortium, including four of the state's accredited MSW programs, initiated in 2012. The MCWEP project developed as a partnership based upon the current consortium model used in the baccalaureate IV-E educational consortium for the state, the Baccalaureate Child Welfare Education Program (BCWEP), in which seven of the state's public and private universities with BSW programs are members.

A unique facet of both the BCWEP and MCWEP is the use of learning communities. The learning community consists of quarterly daylong meetings of all MSW IV-E students from all four partnering universities. Students meet as cohorts based upon year of study 
(the program typically takes 3-4 years as part-time study only), and also as a large group. Learning communities provide the opportunity to synthesize the students' MSW curriculum, field placement experiences, CPS agency integration, and to infuse critical thinking exercises, with self-care and leadership development. The learning communities provide an enhanced learning environment for students, who are mid-level supervisors, to establish a support network among colleagues and faculty, and cultivate innovation in their ideas and strategies to support ongoing reform efforts within the agency.

In addition to the learning communities, MCWEP students are required to take two courses based upon national models of evidence-based curriculum. One course focuses on Leadership and Supervision in Child Welfare; the other is Trauma-Informed Child Welfare Practice (TICWP), which is the focus of this analysis. The TICWP course was adopted from the NCTSN's Core Curriculum for Childhood Trauma (CCCT; Layne et al., 2011). Students receiving the trauma course through the MCWEP program, take the course with an NCTSN certified instructor, and are subjects in the national data collection. Both Fordham University and Stockton University's Institutional Review Boards have approved the research, and students were provided with informed consents for each respective data collection effort.

\section{National Child Traumatic Stress Network Core Curriculum}

The NCTSN was established in 2000 under the Children's Health Act (2000), and has developed a comprehensive empirically-based national model for addressing trauma. Over the past decade, NCTSN has cultivated workgroups through networks of professionals and academics from across the country to formulate an evidence driven curriculum. The National Center for Social Work Trauma Education and Workforce Development, a member of the SAMHSA-funded NCTSN, developed the CCCT for child welfare with the goal of creating a high caliber and evidence informed trauma curricula for dissemination in social work education.

There have been $55 \mathrm{CCCT}$ social work professors certified through the yearlong learning collaborative (over 6 years), open for ongoing participation to maintain fidelity to the teaching framework and structure of the course. Once certified, faculty have some flexibility to tailor content or style within reason. For example, in the MCWEP program some adaptation was necessary since our students are acting supervisors within the organization, occupying slightly different roles than those for which the course content was designed. Since most MCWEP students/supervisors have over a decade of experience in the New Jersey state child welfare system, some organization of the materials was altered to emphasize the importance of their supervisory roles. In addition, because they are well positioned to catalyze agency change in practice, additional depth underscoring the effort toward a trauma-informed agency and developing trauma-informed systems of care is included.

The Center's technical report details the findings from data (2010-2016), from 55 faculty teaching at 36 schools, with 79 separate offerings of the course, and 985 matched (using participant designed unique identifiers) pre- and posttest student surveys (Popescu, Richards, Strand, \& Abramowitz, 2016b). The evaluation of the CCCT over six years 
resulted in ongoing revising of course content and delivery, for overall improvement and enhancement. The main objectives of the course as identified in the technical report are "to increase the students' trauma knowledge, skills, and confidence in relation to the 12 Core Concepts of Trauma" (Popescu et al., 2016a, p. 106). The main measure of these indicators comes from the Core Concept Confidence Scale (designed by Popescu \& Moller, 2010; revised in 2012), in addition to general demographics and student learning objective questionnaires. In the national cohort, researchers at The Center found a statistically significant increase in student confidence, indicating a significant gain in confidence applying the Core Concepts of Trauma (In the national aggregate data, there was an increasing trend in post test scores from year to year, indicating that the ongoing adjustment and integration of course feedback was useful in improving the course outcomes over time (Popescu et al., 2016a).

Findings from The National Center for Social Work Trauma Education and Workforce Development Report: MCWEP Data. In addition to national aggregate data report on learning and course outcomes, collected by class, the Center provides an individualized technical report for each individual institution based upon the pre and posttest data collected each semester. The individualized data report is produced so each instructor can assess the outcomes of their specific class at their institution. MCWEP data provided to The Center for 2015 and 2016 cohorts indicate improvement between pre- and posttest, measured using a matched t-test for each of the 2015 and 2016 classes (Table 1).

Table 1. MCWEP TICWP Overall Student Confidence in Core Concepts of Trauma

\begin{tabular}{|l|c|c|c|c|}
\hline Year & Pretest mean & Posttest mean & t-test & Wilcoxon Signed Ranks \\
\hline $2015(\mathrm{n}=11)$ & 6.13 & 7.68 & $p=.013$ & $p=.043$ \\
\hline $2016(\mathrm{n}=18)$ & 5.12 & 8.39 & $p=.001$ & $p=.018$ \\
\hline
\end{tabular}

Scale 1-9, $1=$ not confident at all, $9=$ completely confident

Mirroring the national aggregate data, the data for the MCWEP specific classes indicates an increase in the primary objective of the course, student confidence in applying the Core Concepts of Trauma (Popescu et al., 2015; 2016b). While the sample size for each analysis is small, which limits the generalizability of these findings, the MCWEP data reflect a trend similar to the national data, and provide a class by class assessment of student confidence for longitudinal consideration; akin to how one might use course evaluation data in teaching.

\section{Outcomes of the MCWEP Trauma-Informed Child Welfare Course}

Methods. In order to assess the impact of the TICWP course in increasing the knowledge of supervisors with regard to trauma, and their ability to apply the concept to their work, including integrating their knowledge, MCWEP has collected independent data through three different formats; self-efficacy surveys, overall MCWEP survey, and an exit survey. The data collected by MCWEP is intended to compliment and supplement the reports generated from the pre and posttest data collected and compiled by The Center (Popescu et al., 2015; 2016b). 
The first source of program evaluation data supplemental data is the self-efficacy survey given to each student at the end of each semester to capture their perceptions of their learning and ability to apply their knowledge. The second is the overall MCWEP program survey which is sent each year to all current students, and the third is the exit survey, which is sent to students who are graduating.

Table 2. Self-Efficacy of TICWP Students with Identified Trauma Practice Behaviors ( $n=54)$

\begin{tabular}{|c|c|c|c|c|c|}
\hline \multirow[b]{2}{*}{ Trauma Competency/Practice Behavior } & \multirow[b]{2}{*}{ Min } & \multicolumn{3}{|c|}{ \% Rating } & \multirow{2}{*}{$\underline{\text { St. }}$} \\
\hline & & $\operatorname{Max}$ & 4 or 5 & Mean & \\
\hline $\begin{array}{l}\text { 1. I am able to integrate the concept of "child traumatic stress" in } \\
\text { case practice and supervision by knowing what types of } \\
\text { experiences constitute childhood trauma and utilize a trauma- } \\
\text { informed lens to manage child welfare cases. }\end{array}$ & 4 & 5 & 100 & 4.8 & 0.42 \\
\hline $\begin{array}{l}\text { 2. I am able to apply knowledge of how traumatic experiences } \\
\text { affect brain development and memory and understand the } \\
\text { relationship between a child's lifetime trauma history and his } \\
\text { or her responses through comprehensive case planning. }\end{array}$ & 3 & 5 & 98 & 4.5 & 0.54 \\
\hline $\begin{array}{l}\text { 3. I can articulate how trauma has an impact on the behavior of } \\
\text { children over the course of childhood and how child traumatic } \\
\text { stress is exacerbated over time by ongoing stressors (including } \\
\text { separation from/loss of caregivers, and/or foster placement) in } \\
\text { a child's environment and within the child welfare system. }\end{array}$ & 4 & 5 & 100 & 4.6 & 0.50 \\
\hline $\begin{array}{l}\text { 4. I am able to identify and promote the utilization of trauma- } \\
\text { sensitive interventions such as strategic referrals to timely, } \\
\text { quality, and effective trauma-focused interventions and trauma- } \\
\text { informed case planning with multi-disciplinary teams. }\end{array}$ & 3 & 5 & 96 & 4.5 & 0.57 \\
\hline $\begin{array}{l}\text { 5. I can articulate how the impact of traumatic stress can be } \\
\text { prevented and/or mitigated by trauma-informed responses of } \\
\text { child welfare workers and child welfare systems. }\end{array}$ & 3 & 5 & 94 & 4.5 & 0.61 \\
\hline $\begin{array}{l}\text { 6. I am able to consider how cultural factors influence the manner } \\
\text { by which children may identify, interpret, and respond to } \\
\text { traumatic events during the case practice process. }\end{array}$ & 3 & 5 & 98 & 4.5 & 0.54 \\
\hline $\begin{array}{l}\text { 7. I am able to identify the impact of secondary traumatic stress } \\
\text { (STS) on child welfare workers and employ appropriate } \\
\text { interventions. }\end{array}$ & 3 & 5 & 96 & 4.4 & 0.57 \\
\hline $\begin{array}{l}\text { 8. I support Child and Family Services Review (CFSR) goals of } \\
\text { safety, permanency, and well-being by increasing skills to } \\
\text { effectively serve children and families (biological and } \\
\text { resource) in the child welfare system that have experienced } \\
\text { traumatic stress. }\end{array}$ & 4 & 5 & 100 & 4.5 & 0.50 \\
\hline
\end{tabular}

Note. (Five-point Likert Scale, from 1 (very much disagree) to 5 (very much agree).

Self-Efficacy surveys ask students to rate the degree to which they agree with statements regarding Trauma-Informed Child Welfare Competencies and Practice Behaviors. These data were collected over four class cohorts (2013-2016). Responses were based on a five-point Likert scale from 1 (very much disagree) to 5 (very much agree). Means on individual items range from 4.44 to 4.78. Students consider themselves capable 
in all eight categories in the CCCT TICWP competencies. The 2016 (not shown) cohort has the highest overall self-assessment means, indicating that improvements in course structure, instruction, and student perceptions of self-efficacy in the competencies are occurring.

Perhaps the most significant indicator of the magnitude of the impact of the TICWP course in the MCWEP program upon the New Jersey State CPS agency comes from the overall qualitative program assessment surveys students complete annually. A thematic analysis was conducted by study authors, once consensus on coding was reached, and ambiguities resolved. A priori categories, anchored in the overarching questions, were considered the guiding framework for coding and developing themes in the analysis, based upon grounded theory techniques (Corbin \& Strauss, 2007).

In the analysis, responses from three questions included repeated thematic comments around the impact of the TICWP course. They are: 1) What are the strengths of MCWEP (Table 3); 2) How well do you think MCWEP is preparing you to be a more impactful supervisor at DCPP (Table 4); 3) Do you feel you are being prepared to play a role in the transformation of New Jersey's public child welfare system?

Five themes emerged across the three questions as described in Tables 3 and 4 below:

- Supervision

- Secondary Traumatic Stress

- Change in language

- Change in perspective/thinking/understanding

- Importance of trauma history

\begin{tabular}{|l|l|l|}
\hline \multicolumn{1}{|l|}{ Table 3. Program Strengths } \\
\hline \multicolumn{1}{|c|}{ Theme } & \multicolumn{1}{c|}{ Common Code } & \multicolumn{1}{c|}{ In Their Voice } \\
\hline Supervision & $\begin{array}{l}\text { Strengthen skills } \\
\text { and incorporate } \\
\text { more clinical } \\
\text { supervision }\end{array}$ & $\begin{array}{l}\text { "The program has strengthened my supervisory } \\
\text { skills by helping me to help my workers and } \\
\text { supervisors understand the impact of trauma on } \\
\text { the families we serve." }\end{array}$ \\
\hline $\begin{array}{l}\text { Secondary } \\
\text { Traumatic Stress }\end{array}$ & Recognition & $\begin{array}{l}\text { "Importance of recognizing STS and burnout is } \\
\text { something I am constantly on the lookout for } \\
\text { now." }\end{array}$ \\
\hline
\end{tabular}

When asked about feeling prepared to play a role in the transformation of New Jersey's public child welfare system, there was a strong consensus that students, indeed, feel prepared. In fact, $88 \%$ (44/50) respondents indicated they felt they are more prepared to play a role in the agency's transformation. Despite the majority of students affirming, many acknowledged that they experienced some tentativeness about the pace of the agency, and concern for the readiness of the agency to accommodate the transformation, for example:

I do feel that I am prepared, but I don't think New Jersey is prepared. We learn about different things our families need to be successful but they are not available for us to implement. An example of this is more trauma-informed services. 


\begin{tabular}{|c|c|c|}
\hline Theme & Common Code & In Their Voice \\
\hline \multirow[t]{3}{*}{ Supervision } & Strengthening skills & $\begin{array}{l}\text { "It teaches what supervisors need to know and } \\
\text { equip themselves for working in the field." }\end{array}$ \\
\hline & Access to tools & $\begin{array}{l}\text { "..continue using the theories and information in } \\
\text { my day-to-day work during case consultation." }\end{array}$ \\
\hline & Change in delivery & $\begin{array}{l}\text { "I have already seen a change in my } \\
\text { supervision." } \\
\text { "The course was extremely useful to my case } \\
\text { practice." } \\
\text { "It has definitely changed my way of thinking } \\
\text { when providing supervision on case." }\end{array}$ \\
\hline $\begin{array}{l}\text { Secondary } \\
\text { Traumatic Stress }\end{array}$ & $\begin{array}{l}\text { Acknowledgement of } \\
\text { existence }\end{array}$ & $\begin{array}{l}\text { "I remind my workers and supervisors that they } \\
\text { are incapable of providing effective intervention } \\
\text { if their own baggage is too heavy." } \\
\text { "Beyond speaking, I am able to step back and } \\
\text { focus on what trauma exposure has done to my } \\
\text { children and staff." }\end{array}$ \\
\hline $\begin{array}{l}\text { Change in } \\
\text { Language }\end{array}$ & $\begin{array}{l}\text { Adaptation of trauma } \\
\text { focus lens }\end{array}$ & $\begin{array}{l}\text { "These classes provide the language necessary } \\
\text { to invoke change in how we deal with families } \\
\text { as well as how to effectively supervise." } \\
\text { "The class has changed my dialect. I speak } \\
\text { about terms that are foreign to the workforce } \\
\text { and it makes them want to learn more about it." }\end{array}$ \\
\hline \multirow[t]{3}{*}{$\begin{array}{l}\text { Change in } \\
\text { Perspective }\end{array}$} & $\begin{array}{l}\text { Knowledge } \\
\text { acquisition }\end{array}$ & $\begin{array}{l}\text { "The TICWP elective was so informative that I } \\
\text { will be able to use all I learned in that class to } \\
\text { continue to service my clients in a more } \\
\text { sufficient way when dealing with trauma." } \\
\text { "The eye opening moments I had in Trauma in } \\
\text { Child Welfare will stay with me throughout my } \\
\text { career." } \\
\text { "The fact that we were exposed to trauma focus } \\
\text { speaks volumes. At DCPP we are not exposed to } \\
\text { this type of training." }\end{array}$ \\
\hline & $\begin{array}{l}\text { Additional tools and } \\
\text { resources }\end{array}$ & $\begin{array}{l}\text { "..continue using the theories and information in } \\
\text { my day-to-day work during case consultation." }\end{array}$ \\
\hline & $\begin{array}{l}\text { Understanding of } \\
\text { trauma }\end{array}$ & $\begin{array}{l}\text { "I understand trauma now, clinical trauma, I } \\
\text { also understand how important it is to provide } \\
\text { the correct services for families." } \\
\text { "I am now aware of the importance of reviewing } \\
\text { cases with a trauma focused lens." }\end{array}$ \\
\hline
\end{tabular}




\begin{tabular}{|l|l|l|}
\hline \multicolumn{1}{|c|}{ Table 4. Supervisor Preparation } & \multicolumn{1}{c|}{ In Their Voice } \\
\hline Theme & \multicolumn{1}{|c|}{ Common Code } & \multicolumn{1}{c|}{$\begin{array}{l}\text { "I do think from a more trauma focused/critical } \\
\text { thinking perspective." }\end{array}$} \\
\cline { 2 - 3 } & Need for change & $\begin{array}{l}\text { "It makes no sense to have a child welfare } \\
\text { agency staff that is not first and foremost } \\
\text { educated in the long lasting impact and effects } \\
\text { of child trauma and complex trauma." }\end{array}$ \\
\hline $\begin{array}{l}\text { Importance of } \\
\text { Trauma History }\end{array}$ & Data collection & $\begin{array}{l}\text { "The trauma class made me realize how } \\
\text { important it is to gather a trauma history with } \\
\text { our children and parents." } \\
\text { "We should be making all decisions with the } \\
\text { consideration of past, present, and possibility of } \\
\text { future trauma." }\end{array}$ \\
\cline { 2 - 3 } & Informing the work & $\begin{array}{l}\text { "I feel that making my supervisees aware of } \\
\text { social justice concerns and impacts their work. I } \\
\text { share with them the impact of trauma and the } \\
\text { importance of history informing their work. }\end{array}$ \\
\hline
\end{tabular}

Frustrations with the bureaucratic pace of change that CPS supervisors are encountering as they become trauma-informed create challenges in remaining invigorated as change agents. Students voice the personal preparation, feeling armed with knowledge to make a difference within their agency, but are tentative since they do not know how to begin.

Students are encouraged to take active advocacy roles within the agency to increase change within the organization; and there is opportunity to develop creative strategies to pursue this goal. As the number of graduates completing the program increases, there will be greater dissemination of this empirically driven CCCT in Child welfare, and thus greater the impact on the agency's internal momentum toward becoming a trauma-informed agency.

\section{Discussion and Limitations}

When considering the compelling evidence to suggest that children, caregivers, and workers in the child welfare system all contend with the adversity and suffering that traumatic experiences bring, it seems obvious that CPS agencies should embrace a trauma focused approach to benefit all those involved. ACF released a detailed information memorandum, in response to the 2011 legislative amendments, to provide guidance in both scope and comprehensiveness of how trauma-informed child welfare systems should approach the issue of trauma (ACF, 2012). However, the reality of transforming large bureaucratic child welfare organizations, whether it is at the county or the state level, is a daunting task. The Trauma-Informed Child Welfare Practice course, from the NCTSN, the learning communities, and the overall MCWEP program, have initiated a comprehensive approach to move the agency in the direction of transformation. The MCWEP program strategically educates mid-level supervisors, who are in positions to impact potentially 
thousands of CPS cases around the state, and at the same time mitigate secondary traumatic stress among their workers. Additionally, these supervisors are located in the ranks that will likely vie for leadership positions in the long term. In a recent initiative, spawning from the MCWEP program, students and alumni have formed task groups to inform and assist the agency's policy unit on revising specific policies to be more trauma-informed. The group has been asked by administration to conduct presentations to key leaders around secondary traumatic stress in the work force. Students and alumni have indicated this is a significant stride in having an engaged and open agency.

There are several limitations of the assessment methods that should be considered. First, this study is a small-scale case study. While it can be replicated, the findings cannot be generalized. The TICWP/CCCT classes have had 20 or fewer students in each cohort, and in the first two years $(2012,2013)$, data was collected and reported from only two of the three MSW programs participating in the MCWEP course, making the $\mathrm{N}$ for the course only 11. Also, the technical reports that provide the statistical analysis of the data sent to the National Center for Social Work Trauma Education and Workforce Development were only available for the two most recent course years (Popescu et al., 2015, 2016b), with low rates of matched data, limiting our ability to assess the statistical efficacy of the course in the earliest sections, and longitudinally. Due to ending of the NCTSN contract with The Center, there will be no future reports unless MCWEP continues to replicate the analysis without the assistance of The Center.

The MCWEP Self Efficacy questionnaire uses questions designed to capture not only the transfer of knowledge, but also a student's capacity to apply the knowledge in their case practices. As such, the eight questions may be considered double barreled, and may not elicit full responses. Finally, additional longitudinal data related to retention and employment satisfaction of MCWEP students is needed to better assess type of supervisors the program draws in its applicants and participants. The self-selection process may be creating the impression that agency supervisors are generally highly motivated and engaged, which may not be the case across the agency.

\section{Conclusion}

The Trauma-Informed Child Welfare course is an effective academic course in educating students in the tenets of trauma-informed child welfare practice and when coupled with the learning communities as part of a Title IV-E MSW program, is likely to have a significant impact on the overall direction of the New Jersey state child welfare transformation. In fact, it may be the leading initiative at this point in time, in terms of driving the change from within, particularly with regard to the recommendations of ACF. In addition to informing case practice and supervisory roles, the course and program are cultivating leaders and advocates within the ranks, who will play key roles in the success of the overall agency's transformation to a trauma-informed child welfare agency in the long term.

\section{References}

Administration for Children and Families (ACF) (2012, April 17). Promoting social and emotional well-being for children and youth receiving child welfare services. 
Washington, D.C.: U.S. Department of Health and Human Services, Administration on Children, Youth and Families (ACYF-CB-IM-12-04, Retrieved from http://www.acf.hhs.gov/programs/cb/laws_policies/policy/im/2012/im1204.pdf

Ai, A. L., Foster, L. J. J., Pecora, P. J., Delaney, N., \& Rodriguez, W. (2013). Reshaping child welfare's response to trauma: Assessment, evidence-based intervention, and new research perspectives. Research on Social Work Practice, 23(6), 651-668. doi: https://doi.org/10.1177/1049731513491835

Berthelot, N., Ensink, K., Bernazzani, O., Normandin, L., Luyten, P., \& Fonagy, P. (2015). Intergenerational transmission of attachment in abused and neglected mothers: The role of trauma-specific reflective functioning. Infant Mental Health Journal, 36(2), 200-212. doi: https://doi.org/10.1002/imhj.21499

Blake, A. (2016). Commissioner's Monthly Report: December 2016. New Jersey Department of Children and Families. Retrieved from: http://www.nj.gov/dcf/childdata/continuous/Commissioners.Monthly.Report 12.16.p $\underline{\mathrm{df}}$

Bride, B. E., Jones, J. L., \& MacMaster, S. A. (2007). Correlates of secondary traumatic stress in child protective services workers. Journal of Evidence-Based Social Work, 4(3/4), 69-80. doi: http://dx.doi.org/10.1300/J394v04n03_05

The Child and Family Services Improvement and Innovation Act, Pub. L. 112-34, § 1 (2011).

Corbin, J., \& Strauss A. (2007). Basics of Qualitative Research: Techniques and Procedures for Developing Grounded Theory. Thousand Oaks, CA: Sage Publications, Inc.

Felitti, V. J., \& Anda, R. F. (2014). The lifelong effects of adverse childhood experiences. Chadwick's Child Maltreatment: Sexual Abuse and Psychological Maltreatment, 2, 203-215.

Felitti, V., Anda, R., Nordenberg. D., Williamson, D., Spitz, A., Edwards, V.,... Marks, J. (1998). Relationship of childhood abuse and household dysfunction to many of the leading causes of death in adults: the adverse childhood experiences (ACE) study. American Journal of Preventive Medicine, 14, 245-258. doi: https://doi.org/10.1016/S0749-3797(98)00017-8

Figley, C. R. (Ed.). (1995). Compassion fatigue: Secondary traumatic stress disorders from treating the traumatized. New York: Brunner/Mazel.

Guzkowski, J. (2015, September 24). Social work education key to retaining foster care workers, advocates say. Retrieved from Youth Today http://youthtoday.org/2015/09/social-work-education-key-to-retaining-foster-careworkers-advocates-say/

Hanson, R. F., \& Lang, J. (2016). A critical look at trauma-informed care among agencies and systems serving maltreated youth and their families. Child 
maltreatment, 21(2), 95-100. doi: https://doi-

org.ezproxy.stockton.edu/10.1177/1077559516635274

Kim, S., Fonagy, P., Allen, J., \& Strathearn, L. (2014). Mothers' unresolved trauma blunts amygdala response to infant distress. Social Neuroscience, 9(4), 352-363. doi: https://doi.org/10.1080/17470919.2014.896287

Kisiel, C., Fehrenbach, T., Small, L., \& Lyons, J. S. (2009). Assessment of complex trauma exposure, responses, and service needs among children and adolescents in child welfare. Journal of Child \& Adolescent Trauma, 2(3), 143-160. doi: http://dx.doi.org/10.1080/19361520903120467

Klain, E. \& White, A. (2013). Implementing trauma-informed practices in child welfare. ABA Center on Children and the Law. Retrieved from Child Welfare http://childwelfaresparc.org/wp-content/uploads/2013/11/Implementing-TraumaInformed-Practices.pdf

Ko, S. J., Ford, J. D., Kassam-Adams, N., Berkowitz, S. J., Wilson, C., Wong, M., Brymer, M.J., \& Layne, C. M. (2008). Creating trauma-informed systems: Child welfare, education, first responders, health care, juvenile justice. Professional Psychology: Research and Practice, 39(4), 396-404. doi: https://doi.org/10.1037/0735-7028.39.4.396

Layne, C. M., Ippen, C. G., Strand, V., Stuber, M., Abramovitz, R., Reyes, G., ... \& Pynoos, R. (2011). The Core Curriculum on Childhood Trauma: A tool for training a trauma-informed workforce. Psychological Trauma: Theory, Research, Practice, and Policy, 3(3), 243. doi: https://doi.org/10.1037/a0025039

Lipka, M., \& Graham, T. (2004, February 19). NJ reveals broad plan to fix DYFS: Tragic cases have lent notoriety to the agency. Philadelphia Inquirer. Retrieved from http://articles.philly.com/2004-02-19/news/25373708_1_child-welfare-panel-planhousing-subsidies

Miller, E. A., Green, A. E., Fettes, D. L., \& Aarons, G. A. (2011). Prevalence of maltreatment among youths in public sectors of care. Child Maltreatment, 16(3), 196-204. doi: https://doi.org/10.1177/1077559511415091

National Child Traumatic Stress Network, Child Welfare Committee. (2011). Birth parents with trauma histories and the child welfare system: A guide for judges and attorneys. Los Angeles, CA, and Durham, NC: National Center for Child Traumatic Stress. Retrieved from http://nctsn.org/sites/default/files/assets/pdfs/birth_parents_trauma_guide_judges_fin al.pdf

Nelson-Gardell, D., \& Harris, D. (2003). Childhood abuse history, secondary traumatic stress, and child welfare workers. Child Welfare, 82(1), 5-26.

Noonan, K. G., Sabel, C. F., \& Simon, W. H. (2009). Legal accountability in the servicebased welfare state: Lessons from child welfare reform. Law \& Social Inquiry, 34(3), 523-568. doi: https://doi.org/10.1111/j.1747-4469.2009.01157.x 
O'Donnell, J., \& Kirkner, S. L. (2009). A longitudinal study of factors influencing the retention of Title IV-E master's of social work graduates in public child welfare. Journal of Public Child Welfare, 3(1), 64-86. doi: https://doi.org/10.1080/15548730802690841

Perry, B. D. (2009). Examining child maltreatment through a neurodevelopmental lens: Clinical applications of the neurosequential model of therapeutics. Journal of Loss and Trauma, 14(4), 240-255. doi: https://doi.org/10.1080/15325020903004350

Popescu, M., \& Moller, J. (2012). Core Concept Confidence Scale (Unpublished instrument). Available from Fordham University and Hunter College, The National Center for Social Work Trauma Education and Workforce Development, New York.

Popescu, M., Richards, S., Strand, V., \& Abramowitz, B. (2015). Core Concepts for Trauma Informed Child Welfare Practice: The Richard Stockton College of New Jersey Technical Report, Summer 2015. New York. Fordham University and Hunter College, The National Center for Social Work Trauma Education and Workforce Development.

Popescu, M., Richards, S., Strand, V., \& Abramowitz, B. (2016a). Core Concepts for Trauma Informed Child Welfare Practice: Stockton University Technical Report, Summer 2016. New York. Fordham University and Hunter College, The National Center for Social Work Trauma Education and Workforce Development.

Popescu, M., Richards, S., Strand, V., \& Abramowitz, B. (2016b). Core Concepts for Trauma Informed Child Welfare Practice, Aggregate Report 2010-2016. New York. Fordham University and Hunter College, The National Center for Social Work Trauma Education and Workforce Development.

Pryce, J., Shackelford, K., \& Pryce, D., (2007). Secondary traumatic stress and the child welfare professional. Chicago: Lyceum.

Putnam-Hornstein, E., Cederbaum, J. A., King, B., Eastman, A. L., \& Trickett, P. K. (2015). A population-level and longitudinal study of adolescent mothers and intergenerational maltreatment. American Journal of Epidemiology, 181(7), 496-503. doi: https://doi.org/10.1093/aje/kwu321

Richardson, M., Henry, J., Black-Pond, C. \& Sloane, M. (2008). Multiple types of maltreatment: Behavioral and developmental impact on children in the child welfare system. Journal of Child and Adolescent Traumatic Stress, 1, 317-330. doi: https://doi.org/10.1080/19361520802505735

Schwerdtfeger, K. L., Larzelere, R. E., Werner, D., Peters, C., \& Oliver, M. (2013). Intergenerational transmission of trauma: The mediating role of parenting styles on toddlers' DSM-related symptoms. Journal of Aggression, Maltreatment \& Trauma, 22(2), 211-229. doi: https://doi.org/10.1080/10926771.2013.743941

Strolin-Goltzman, J., Kollar, S., \& Trinkle, J. (2010). Listening to the voices of children in foster care: Youths speak out about child welfare workforce turnover and selection. Social Work, 55(1), 47-53. doi: https://doi.org/10.1093/sw/55.1.47 
Thornberry, T., \& Henry, K. (2013). Intergenerational continuity in maltreatment. Journal of Abnormal Child Psychology, 41(4), 555-569. doi: https://doi.org/10.1007/s10802-012-9697-5

Thornberry, T., Knight, K., \& Lovegrove, P., (2012). Does maltreatment beget maltreatment? A systematic review of the intergenerational literature. Trauma Violence Abuse, 13, 135-152. doi: https://doi.org/10.1177/1524838012447697

Walker, J. (2007). Unresolved loss and trauma in parents and the implications in terms of child protection. Journal of Social Work Practice, 21(1), 77-87. doi: https://doi.org/10.1080/02650530601173656

Watts-English, T., Fortson, B.L., Giblet, N. Hooper, S.R. \& DeBellis, M.D. (2006). The psychobiology of maltreatment in childhood. Journal of Social Issues, 62, 717-736. doi: https://doi.org/10.1111/j.1540-4560.2006.00484.X

Zlotnik, J. (2003). The use of Title IV-E training funds in social work education: An historical perspective. Journal of Human Behavior in the Social Environment, 7(1/2), 5-20. doi: https://doi.org/10.1300/J137v07n01 02

Zlotnik, J. L., \& Pryce, J. A. (2013). Status of the use of Title IV-E funding in BSW and MSW programs. Journal of Public Child Welfare, 7(4), 430-446. doi: https://doi.org/10.1080/15548732.2013.806278

Zlotnik, J. L., Strand, V. C., \& Anderson, G. R. (2009). Introduction: Achieving positive outcomes for children and families: Recruiting and retaining a competent child welfare workforce. Child Welfare, 88(5), 7-21.

\section{Author note:}

Address correspondence to: Robin Hernandez-Mekonnen, Department of Social Work, School of Social and Behavioral Sciences, Stockton University, 101 Vera King Farris Drive, Galloway, NJ 08205, 609-626-5530, Robin.Hernandez-Mekonnen@ Stockton.edu. 